RELACult - Revista Latino-Americana de Estudos em Cultura e Sociedade

Revista Latinoamericana de Estudios en Cultura y Sociedad | Revue Latino-américaine d'Études sur la culture et la société |

Latin American Journal of Studies in Culture and Society

V. 07, nº 01, jan.-abr., 2021, artigo ${ }^{\circ} 2005$ | claec.org/relacult | e-ISSN: 2525-7870

\title{
La construcción del sujeto complejo en la Educación Matemática Decolonial Transcompleja
}

\author{
Milagros Elena Rodriguez ${ }^{1}$
}

\begin{abstract}
Resumen
El sujeto que deviene de la pedagogía de la matemática tradicional es soslayado; la escolaridad impone normas que establecen un orden y relaciones reproductivas que nos obliga a asimilar y repetir los saberes establecidos por la racionalidad hegemónica. En la concientización ecosófica, la ecosofía el arte de habitar en el planeta, propendemos la conformación del sujeto complejo en la Educación Matemática Decolonial Transcompleja como objetivo complejo de investigación. Se realiza la investigación desde la deconstrucción como transmétodo rizomático en la transmodernidad. En el rizoma reconstrucctivo, el sujeto concientizado critico en un dialogo dialéctico-dialógico, se conforma como ciudadano del planeta-tierra en la antropoética; desde la Educación Matemática. Es imperativo así, un des-ligar de las prácticas opresivas de la matemática; para re-ligar el sujeto político que ejerce un poder, que transita en el conocer la matemática compleja con el aporte de las civilizaciones colonizadas, en claros procesos decoloniales; y el hacer vida-cotidiana del habitat popular; en una liberación onto-epiestemológica del sujeto. Rompiendo la imposición Occidental de la matemática.
\end{abstract}

Palabras-Clave: Construcción; Sujeto complejo; Educación Matemática; Decolonial; Transcompleja.

La disciplina aumenta las fuerzas del cuerpo (en términos económicos de utilidad) y disminuye esas mismas fuerzas (en términos políticos de obediencia). En una palabra: disocia el poder del cuerpo; de una parte, hace de este poder una aptitud, una capacidad que trata de aumentar, y cambia por otra parte la energía, la potencia que de ello podría resultar, y la convierte en una relación de sujeción estricta (Michel Foucault, 2008, p.160).

Tenemos el derecho democrático de vivir todos los ciudadanos como humanos (Edgar Morín, 2001a, p.23).

\section{Rizoma transmétodico. El transmétodo como parte interpelaría y reconstructiva en la indagación}

Bajo los lemas iniciales de Michel Foucault y Edgar Morín que nos incitan a pensar que el poder ha estado presente en todas las civilizaciones, dominación que ejerce un dominio que soslaya el cuerpo en todo sentido; y que tenemos el derecho a ser libres y ejercer con responsabilidad ese poder de existir; comenzamos esta investigación transmétodica, más allá

\footnotetext{
${ }^{1}$ Cristiana, Venezolana, PhD en Educación Matemática, Pensamiento y Religaje en la Transmodernidad, PhD. en Ciencias de la Educación, Doctora en Patrimonio Cultural, Doctora en Innovaciones Educativas, Magister Scientiaurum en Matemáticas, Licenciada en Matemática. Docente Investigadora titular a dedicación exclusiva del Departamento de Matemáticas, Docente de Postgrado en Educación, Postgrado en Administración y Postgrado en Biología de la UDO. E-mail: melenamate@ hotmail.com ORCID iD: https://orcid.org/0000-0002$\underline{0311-1705}$
} 
RELACult - Revista Latino-Americana de Estudos em Cultura e Sociedade

Revista Latinoamericana de Estudios en Cultura y Sociedad | Revue Latino-américaine d'Études sur la culture et la société | Latin American Journal of Studies in Culture and Society V. 07, $\mathrm{n}^{\circ}$ 01, jan.-abr., 2021, artigo $\mathrm{n}^{\circ} 2005$ | claec.org/relacult | e-ISSN: 2525-7870

de las erráticas investigaciones modernistas reduccionistas. Propendemos y defendemos la concepción de sujeto complejo que va a deconstruir inteligencia ciega (MORÍN, 1990) bajo la cual ha venido accionando; un sujeto interpelado en su accionar irrespetuoso a la vida y a su propia condición humana. Por eso, en particular en la crisis de la enseñanza de la matemática el sujeto en formación lleva su inteligencia mecánica que colabora en la crisis civilizatoria en cuestión; la Educación Matemática ha aportado su cuota de responsabilidad.

En tal sentido; y en un orden de concientización ecosófica, la ecosofía el arte de habitar en el planeta, propendemos la conformación del sujeto complejo en la Educación Matemática Decolonial Transcompleja como objetivo complejo de investigación. Emmarcada en la línea de investigación: Educación Matemática Decolonial Transcompleja. Realidad que llevaremos a cabo con la deconstrucción rizomática como transmétodo transmoderno transcomplejo. Como puede observar el lector se van avizorando categorías e interrogantes que vamos a ir desmitificando. Solicitamos al lector mente abierta, ojo avizor, apertura de los sentidos para en primer lugar comprender que se trata de una indagación fuera de los cánones establecidos de estructuras impositivas desarrolladas mediante: introducción, desarrollo, resultados y conclusiones. Acá vamos más allá, en un enmarañado ejercicio complejo de construcción. En segundo lugar, la línea de investigación donde se enmarca.

¿Cuál línea de investigación? la Educación Matemática Decolonial Transcompleja (EMDT). Ella es inclusiva, ecosófica y transmoderna, pues el repensamiento que conlleva a la "Educación Inclusiva Ecosófica se da en un proyecto transmoderno en el que no hay posibilidad, para el encubrimiento del otro, ni medidas de opresión que se permitan; los topoi van como un nuevo conocimiento al abrazo de grupos considerados disímiles" (CARABALLO; RODRÍGUEZ, 2019, p. 130). Es importante decolonizar la ciencia matemática ante el Sur, ante la imposición occidental cargada de escepticismo de una matemática apartada para una élite denominados "inteligentes"; inclusive para la colonialidad en el sexo de los matemáticos, desde luego en la matemática para Occidente, "ha costado calar en el mero poder de eficiencia de que las mujeres somos capaces para la matemática, pese a claros ejemplos desde el comienzo de la ciencia” (RODRÍGUEZ, 2020a, p.12).

Se trata de ejercer una verdadera política educativa,

una antropolítica que desmitifique los currículos, el ejercicio de poder en el aula de la matemática como soslayación en las aspiraciones a educarse y llegar a ascender y construir cada día, re-construir sus teorías desde aplicabilidades nuestras, desde la cotidianidad y saberes soterrados desde el Sur. Es la ciencia matemática patrimonio de la humanidad a la que todos podemos aprender, con mente, cuerpo y corazón (RODRÍGUEZ, 2020a, p.12). 
RELACult - Revista Latino-Americana de Estudos em Cultura e Sociedade

Revista Latinoamericana de Estudios en Cultura y Sociedad | Revue Latino-américaine d'Études sur la culture et la société | Latin American Journal of Studies in Culture and Society V. 07, $\mathrm{n}^{\circ}$ 01, jan.-abr., 2021, artigo $\mathrm{n}^{\circ} 2005$ | claec.org/relacult | e-ISSN: 2525-7870

Atendiendo a las ideas mencionadas las madejas tejidas rizomáticas de la indagación refieren a la complejidad de la vida en primer lugar, a la complejidad de las concepciones de la indagación, al transmétodo complejo y transdisciplinar; pero también atienden a la liberación ontoepistemológico del sujeto investigador que va a libremente complejizar la indagación consiguiendo conexiones vías-tejidos-rizomas-mesetas para presentar investigaciones libres de las ataduras imprecisas de imponer verdades acabadas; que caducan en el instante mismo de su interpelación primera.

Todo ello es posible porque el espacio transparadigmático es decolonial planetario, transcomplejidad sólo es posible en lo decolonial planetario, que va fuera de la colonialidad de las mentes, hacer, ser, soñar, pensar y vivir; sin incisiones de superioridades en la libertad de creación divina a la que Dios nos imprime su sabiduría y semejanza a su hijo Jesucristo. En la madeja tejida, se atiende al rizoma, a ser exhibida en la segunda obra teórica que es la continuidad de Anti-Edipo, nombrada en este caso como Mil mesetas (DELEUZE; GUATTARI, 2002); se le designa tres enmarañadas significancias al rizoma:

\footnotetext{
Pensar no es representar (no se busca una adecuación con una supuesta realidad objetiva, sino un efecto real que vuelve a lanzar la vida y el pensamiento, desplaza sus desafíos, los lleva más lejos y a otra parte); 2) no hay un comienzo real sino en el medio. Allí donde la palabra "génesis" recupera plenamente su valor etimológico de "devenir", sin relación con un origen; 3) si todo encuentro es "posible" en el sentido en que no hay razón para descalificar a priori algunos caminos más que otros, no por ello todo encuentro es seleccionado por la experiencia (algunos montajes, algunos acoplamientos no producen ni cambian nada) (ZOURABICHVILI, 2007, p.95).
}

De allí, el rizoma se complejiza con todo lo expuesto en el texto de la indagación; y al estilo en la Biología, las raíces continúan al tallo y este a las hojas, pero siempre estas regresan a la raíz. Por ello, por ejemplo, podemos estar concluyendo y al mismo tiempo conectando con la problemática que se resiste a ser ocultada en el proceso deconstructivo transmetódico de la indagación; inédita de Rodríguez (2019a).

Trata la deconstrucción rizomática, en el caso de la crisis de la Educación Matemática en la formación del sujeto de develar, "la posibilidad del decaimiento de los dogmas epistemológicos y metodológicos y dar opción a una mirada de saberes interconectados con todas las áreas del saber y los saberes soterrados" (RODRÍGUEZ, 2019a, p.1). A ello vamos con pasos incisivos, complejos para que la realidad no sea vedada e imposibilitada de revelar por lo coloniales pensamientos escuetos del sujeto investigador.

Vamos entonces a desarrollar actos subversivos, pues "deconstruir envuelve un acto creativo respaldado en la decisión, donde también se reconstruye, una reconstrucción esperanzadora que intercede en el discurso" (RODRÍGUEZ, 2019a, p.1). Entonces 
RELACult - Revista Latino-Americana de Estudos em Cultura e Sociedade

Revista Latinoamericana de Estudios en Cultura y Sociedad | Revue Latino-américaine d'Études sur la culture et la société | Latin American Journal of Studies in Culture and Society V. 07, $\mathrm{n}^{\circ}$ 01, jan.-abr., 2021, artigo $\mathrm{n}^{\circ} 2005$ | claec.org/relacult | e-ISSN: 2525-7870

seguiremos caminos diferentes en el discurso; pues es de hacerse conciencia del sujeto complejo que va a va al devastación de las epistemologías coloniales, a la construcción de transepistemologías como iniciación de distintos espacios que consientan a los sujetos subalternos sonterrados, articular sus propias formas de conocimiento, soterrados, desvalorizados u olvidados ((RODRÍGUEZ, 2019a). Y ello ocurre tanto en el sentido impuesto colonial de la manera de hacer matemática en la educación y de lo que es el sujeto colonial desde hace más de 500 años en el soslayado Sur, incluyendo las naciones invadidas y masacradas mucho antes del Sur.

En la investigación nos mostramos inclusivos, y vamos con la deconstrucción transmetódica a "estar presente incisivamente dando un viraje a las indagaciones con esa visión transparadigmática. Es un ir y venir que va a la criticidad; pero también a la reconstrucción" (RODRÍGUEZ, 2019a, p.9). Ello lo realizamos desde el presente rizoma, envolviendo con el Rizoma crisis. El sujeto en la Educación Matemática hoy; Rizoma categorización. El sujeto político, social y sujeto histórico como parte de la historia de concepciones reduccionistas; Rizoma reconstrucción. La construcción del sujeto complejo en la Educación Matemática Decolonial Transcompleja y Rizoma cierre. Conclusiones de primicias.

\section{Rizoma crisis. EI sujeto en la Educación Matemática hoy}

En la Educación Matemática hoy hay crisis pendiente que debemos avocarnos; por ello, en la consideración del sujeto en dicha educación emitimos realidades a considerar urgentemente. La educación matemática ha venido siendo "capaz de operar como un arma secreta del imperialismo occidental" (SKOVSMOSE, 2012, p. 270). Por ello, es urgente, desde una educación matemática decolonial, para la resistencia que involucra desde un trasfondo dialógico, educar en la reflexividad, el asombro, "la resistencia y la percepción de las transformaciones sociales, incorporar la teoría compleja, invitar a integrar la relación individuo-sociedad-especie, trilogía desde la cual se pueden superar las cegueras educativas y reorganizar el conocimiento" (ANDRADE; LEGUIZAMO; VERGARA, 2018, p. 495). Rescatar y salvaguardar transversalmente los conocimientos matemáticos del Sur es urgente en la vida de las personas (RODRÍGUEZ, 2020a).

Las realidades que vive el sujeto subyugado en la Educación Matemática hoy estriba en primer lugar, en que el proceso de enseñanza-aprendizaje se basa en la transmisión de saber científico y hacer repetitivo determinado por la imposición de un pensamiento único, donde el pensar y actuar están guiados por estrictos pasos se algoritmos desmitificando los 
RELACult - Revista Latino-Americana de Estudos em Cultura e Sociedade

Revista Latinoamericana de Estudios en Cultura y Sociedad | Revue Latino-américaine d'Études sur la culture et la société | Latin American Journal of Studies in Culture and Society V. 07, $\mathrm{n}^{\circ}$ 01, jan.-abr., 2021, artigo $\mathrm{n}^{\circ}$ 2005 | claec.org/relacult | e-ISSN: 2525-7870

saberes cotidianos y culturales de la matemática. El dialogo de saberes entre los mal denominados no científicos de las matemáticas y los saberes científicos no son permitidos; en tanto los primeros que pertenecen a la subjetividad del discente no son tomados en cuenta.

En segundo lugar, y no por ello menos importante, el sujeto es desde la pedagogía modernista un sujeto universal y validado para cualquier civilización; siendo la principal la tomada en cuenta la Occidental, desde allí es moldeado en su ser, pensar y hacer; más también sentir la ciencia matemática como inalcanzable, para unos pocos denominados inteligentes. Las estrategias de solución de problemas en la matemática son reduccionistas y no atenientes a la complejidad del ser humano (RODRÍGUEZ, 2020b).

La racionalidad del sujeto formado en la Educación Matemática modernista, se funda en la objetividad; pretendido objetivo de racionalizar la realidad, de encontrar verdades acabadas y de los datos que la conforman, lo que las matemáticas de la complejidad han desmitificado con entre otros aportes la teoría de la complejidad. Este modelo único de sujeto, los que entran por el filo de esa enseñanza son aracionales, impositivos, coloniales e irrespetuosos a la diversidad de la vida y condición humana; ellos devienen de una formación esquiva y parcelada de lo que es la verdadera matemática: ciencia viva, con mente, cuerpo y corazón que deviene de los procesos de formación más íntimos del ser: dialogantes y dialécticos que se execran en el aula. Los seres que no entran en la conformación de esa matemática escueta sufren de trastornos psíquicos, desde sus primeros niveles de educación; se sienten fracasados y generalmente no realizan sus proyectos de vida; con bellas excepciones en grandes didácticas de la matemática, casos maravillosos de libertad en el aula.

El sujeto que deviene de la pedagogía de la matemática tradicional es soslayado; la escolaridad impone normas que establecen un orden y relaciones reproductivas que nos obliga a asimilar y repetir los saberes establecidos por la racionalidad hegemónica; en ello hay muchos estudios en la biopolítica del poder (FOUCAULT, 1990). Las instituciones educativas son portadora de dominación y encuadramiento mental, emparejamiento en el deber ser de lo que se cree debe funcionar el ser humano; así todo sistema de educación como lo constituye la escuela es una forma política de mantener o de modificar la adecuación de los discursos, con los saberes y los poderes que implican (FOUCAULT, 1990).

Debido a que la matemática en el aula no se presenta con los procesos dialógicos de los sujetos educandos, estos no llegan a procesos metacogntivos de alto nivel reflexivo; sino que la mayoría impone una repetición lejos del dialogo dialógico-dialectico deseado. ¿Consecuencias en la psique del niño y de la niña de la práctica descrita anteriormente? La matemática en el ser humano puede permitir dirigir su intelecto, desarrollar sus proceso 
RELACult - Revista Latino-Americana de Estudos em Cultura e Sociedade

Revista Latinoamericana de Estudios en Cultura y Sociedad | Revue Latino-américaine d'Études sur la culture et la société | Latin American Journal of Studies in Culture and Society V. 07, $\mathrm{n}^{\circ}$ 01, jan.-abr., 2021, artigo $\mathrm{n}^{\circ} 2005$ | claec.org/relacult | e-ISSN: 2525-7870

mentales, la toma de decisiones y el ser y estar en el mundo; es de tan delicado cuidado la oportuna enseñanza de la matemática que "el que no posee una educación matemática se halla privado de algo que es esencial al hombre" (PÉREZ, 1980, p.42); son palabras del matemático George Papy en una entrevista realizada por Augusto Pérez en la Argentina y que sigue viva en los instrumentos de soslayación en la Educación Matemática.

Por ejemplo, del número, el símbolo como tal de cualquier número natural es una abstracción más la representación del número en sus juegos es una concreción. ¿Qué sucede en los procesos mentales de la niña y del niño en el contacto con el docente en sus primeros niveles? El docente impone la abstracción del número como proceso continuo de repetición y lo relaciona el docente con sus juegos. No con los juegos de los niños; estos comienzan a sentirse enajenados del hogar y de la escuela; viven una doble fractura de seriedad impuesta fuera de su seriedad que son sus juegos. Doble imposición porque el docente le impone su clase fuera de sus procesos dialógicos-dialécticos; le es castigado con un no está bien, esta malo no sirve; cuestión que el niño y niña no conoce en sus juegos; es doble porque al llegar a su hogar a la hora de hacer las asignaciones pendientes de la educación inicial muchas veces los padres y representantes le imponen la repetición de las tareas aisladas de sus vidas.

Es así como, en la crisis de la enseñanza de la matemática, su colonialidad impuesta hasta hoy con nuevos artefactos de soslayación de los sujetos educandos con el docente ya sometido a prácticas coloniales, con sus excepciones maravillosas de grandes maestros que despiertan el amor por la ciencia, los avances en tal materia; en realidad en un buen número, "la matemática tradicional, o más bien, la metodología tradicional de enseñanza de las matemáticas, desarrolla la pasividad, la obediencia" (PÉREZ, 1980, p.42). Esa obediencia es la que el adulto docente adquirió del círculo interminable de la soslayación.

\section{Rizoma categorización. El sujeto político, social y sujeto histórico como parte de las concepciones reduccionistas}

La noción de sujeto histórico enmarcada en la del sujeto complejo a construir en investigación es de dilatado cuidado en primero lugar porque permea la noción de identidad; es necesario en la construcción discursiva un sujeto que dejando de ser objeto en su descolonización pasa ser sujeto de cambios ateniente a su propia historia de creación. Es así como se atiende a un sujeto de

Conocimiento-reconocimiento es lo que designo como solidaridad. Estamos tan acostumbrados a concebir el conocimiento como un principio de orden sobre las cosas y sobre los otros que es difícil imaginar una forma de conocimiento que funcione como principio de solidaridad. Tal dificultad es un desafío al que debemos enfrentarnos (SANTOS, 2003, p.31). 
RELACult - Revista Latino-Americana de Estudos em Cultura e Sociedade

Revista Latinoamericana de Estudios en Cultura y Sociedad | Revue Latino-américaine d'Études sur la culture et la société |

No hay duda de tamaño desafío de sujeto que atiende una concepción de ciudadano, en palabras redundantes de la autora; es el activo que antes cuando era visto como objeto en esa colonización pasa ser él que define y es constructor de su propia historia y abre caminos definitivos para su realidad a favor del bien común, el de sus semejantes. El sujeto es creador de historicidad: de la capacidad de intervenir sobre su propia historia. Él es el producto de una historia, de la cual él busca llegar a ser sujeto (TOLEDO, 2012). El sujeto también es productor de historias, puesto que cuenta con la capacidad de construir narraciones.

Es en ese renacer de sujeto al estudiar la subjetividad que

Ese "despertarse" del sujeto del sueño, ese aparecer el sujeto en el mundo desde la subjetividad como sensibilidad pre-consciente (pre-cognitiva) es uno de los temas de Levinas. El otro es que el contenido de la pulsión (afecto, apetito, deseo, etc.) es lo gozado (su acto propio el "gozo"), mientras que el contenido del acto cognitivo (entendimiento, razón, interpretación, comprensión, etc.) es lo conocido (su acto propio es la "verdad") (DUSSEL, 1999, p.3).

Nótese la excelencia en su complejidad de ese transformar de sujeto a la que el autor anterior ejemplifica. De allí es menester una noción compleja de sujeto; pues vivimos en una dualidad en la noción de sujeto (MORÍN, 2002). Esa dualidad es el sujeto que es objeto considerado así en su colonización. Por ello, este autor padre del transparadigma complejo afirma que el sujeto debe desarrollar la condición humana, luchar contra el egoísmo y la crueldad, comprometernos con la compasión y la solidaridad (MORÍN, 2002).

En la noción de sujeto complejo opositora a las concepciones de la descomposición del sujeto, pues interesan fundamentalmente los elementos que apuntan a la transformación del sujeto tradicional, a través de las nuevas formas de sentir, hacer, reflexionar, intersubjetivamente (GIDDENS, 1995). Es decir, el sujeto complejo se ocupa de las conflictivas relaciones que ligan a la psique con la conciencia discursiva, ante los procesos de socialización (imágenes parentales, lenguaje, conciencia práctica cotidiana, entre otros; así entiende que se da paso, en un proceso permanente, a la conformación de sujetos.

El sujeto largamente en la colonización es vista desde el otro como objeto y en ese reconocimiento del otro como sujeto histórico esta la descolonización largamente pensada desde Enrique Dussel. Así mismo, se habla se afirma que el sujeto

Se construye a partir de una tradición epistemológica marginada y desacreditada de la modernidad: el conocimiento-emancipación. En esta forma de conocimiento la ignorancia es el colonialismo, y el colonialismo se define por la concepción del otro como objeto y, consecuentemente, el no reconocimiento del otro como sujeto. En esta forma de conocimiento, conocer es reconocer y progresar en el sentido de elevar al otro de la condición de objeto a la condición de sujeto (SANTOS, 2003, p.26).

Ese sujeto histórico de dualidad con el objeto debe 
RELACult - Revista Latino-Americana de Estudos em Cultura e Sociedade

Revista Latinoamericana de Estudios en Cultura y Sociedad | Revue Latino-américaine d'Études sur la culture et la société | Latin American Journal of Studies in Culture and Society V. 07, $\mathrm{n}^{\circ}$ 01, jan.-abr., 2021, artigo $\mathrm{n}^{\circ} 2005$ | claec.org/relacult | e-ISSN: 2525-7870

Superar la clásica dicotomía entre el sujeto y el objeto que sirve de fundamento a toda la filosofía burguesa. El acento no está puesto sobre lo que une, sino en lo que separa. Tampoco en la historia que construí contractualmente asociada con otros individuos racionales, sino en un mito en el que participo (MAFFESOLI, 2004).

Juega el sujeto histórico un papel preponderante en la cultura; si a ella la vemos como los procesos de producción y transmisión de sentidos que constituyen el universo simbólico de las personas, los grupos sociales y la sociedad en su conjunto.

De tal realidad anterior los sujetos históricos deben desplegar sus intelectos, creatividad sentir para disponer en espacios culturales anti-colonizadores y alternativos a la pérdida de su cultura que contribuyan a producir y transmitir sentidos y bienes simbólicos que se inscriban hacia la construcción, desde las relaciones cotidianas y hasta las relaciones sociales, económicas y políticas estructuradas en los valores de la solidaridad, la diversidad, la pluralidad, la justicia, la dignidad del ser humano.

No siempre el sujeto ha tenido esta función. La tarea de sujetos históricos las han desempeñado en la historia de diversas maneras; "el proletariado, el burgués pudieron ser "sujetos históricos" que tenían una tarea por realizar. Tal o cual genio teórico, artístico o político pudo entregar un mensaje cuyo contenido indicara la dirección que había que seguir" (MAFFESOLI, 2004, p.37). Terrible realidad; no en vano es llamado al sujeto histórico el tercer eje o coordenada de la historia.

De todas estas aristas que abarcan los investigadores y que la misma categoría sujeto histórico hay muchas cosas por responder; Giddens (1995) afirma que esto plantea que se presentan una serie de interrogantes que el sujeto tendría que ser capaz de responder, sobre cuestiones existenciales básicas que afloran en especial en los momentos de crisis individual o social.

El sujeto histórico el convocado a transformar su realidad; es a su vez constructor de la historia y un agente de transformación en la historia. No es por eso un ente homogéneo, sino que está combinado por la rica y compleja diversidad que concibe la vida social y política, pero que confluyen temporal y parcialmente en un proyecto; en puntos de acuerdos.

Finalmente en este breve entremés de la significancia del sujeto histórico es bueno clarificar que este se define y se activa social, cultural y políticamente, en función de su postura cultural, política e ideológica contraria y deseable a la colonización a la que se ha visto sometida y de la cual despierta y en cuanto actor intérprete del cambio social y acarreador de un proyecto de transformaciones que se inscribe hacia una nueva humanidad.

Por otro lado, en la asista compleja hablar de sujetos políticos implica edificar nuevas representaciones de renovación del mundo, es apostar una vez más erigir desde la alteridad 
RELACult - Revista Latino-Americana de Estudos em Cultura e Sociedade

Revista Latinoamericana de Estudios en Cultura y Sociedad | Revue Latino-américaine d'Études sur la culture et la société | Latin American Journal of Studies in Culture and Society V. 07, nº 01, jan.-abr., 2021, artigo n 2005 | claec.org/relacult | e-ISSN: 2525-7870

personas encauzadas hacia la tarea y ejercicio de actuar; aquel ser que es ante todo el ser humano que interactúa desde lo cotidiano de su convivencia, por medio del diálogo y la comunicación, donde surge una especie de demanda política. Morín (2002) habla desde estas ideas del sujeto que vuelve sus acciones al mundo; al servicio de la salvación del planeta. Es el sujeto, en busca de la verdad, se constituía en sujeto filosófico capaz de gobernarse y gobernar a los demás para el logro del bien común.

En efecto, Morín (2002) rescata esta idea de sujeto y va más allá, por las múltiples modificaciones de la historia da la noción de sujeto, por eso nos plantea que vivimos en una dualidad en la noción de sujeto porque por un lado sostenemos el alma, el espíritu, la sensibilidad, la filosofía, la literatura y por otro lado las ciencias, las técnicas, la matemática y no podemos encontrar el menor sostén para la noción de sujeto en la ciencia clásica.

El sujeto político se construye pero basado no sólo en las nuevas formas de conciencia, considero va más allá, y esto porque debe trascender el mundo individual y la idea de sí mismo, es la experiencia del otro, de lo que él se nutre desde este convivir. Toledo (2012) al respecto afirma el sujeto asume un rol activo en su relación con la historia y la estructura social; así el sujeto construye su identidad. El sujeto es un ser activo que puede modificar sus prácticas y las estructuras en las cuales se encuentra inserto.

El sujeto es actor "como agente sistémicamente funcionalizado lo denominaremos por ello actor. Los actores constituyen sistemas, organizaciones, movimientos, grupos, clases sociales, entidades intersubjetivas" (DUSSEL, 1999, p.8). No hay dudas que estas son caracterizaciones del sujeto político. De aquel sujeto que debemos ayudar a construir desde la educación, acompañar procesos, la disposición y adaptación a nuevas formas de ser y hacer educación, transformar modelos y prácticas totalitarias de control y de ejercer autoridad al interior del aula, proponer nuevas pedagogías basadas en la alteridad, el respeto la diversidad del otro frente a mí, con su vivencia y experiencia de vida; es ir al sentido de lo humano.

En vista de que el sujeto político ejerce un poder, quisiera dejar una serendipia, esto es una sorpresa afortunada que marca caminos esenciales de investigación, que surge de las lecturas para la continuación de la línea de investigación; es la noción de sujeto político en pues el introduce una nueva categoría referencia de importancia capital, afirma el autor "cuando se define el ejercicio del poder como un modo de acción sobre las acciones de los otros (...) se incluye un elemento muy importante: la libertad” (FOUCAULT, 1986, p.790). El poder sólo se ejerce sobre sujetos libres, y sólo en tanto ellos sean libres.

En este asunto de la libertad a la cual alude el autor anterior se estudia en otras obras, 
En este juego la libertad bien puede aparecer como la condición para ejercer el poder (al mismo tiempo que es su precondición, ya que la libertad debe existir para que el poder pueda ser ejercido, y a la vez ser su apoyo permanente, ya que sin la posibilidad de resistencia, el poder podría ser equivalente a la imposición física) (FOUCAULT, 2001, 315).

Mientras que el sujeto social, envuelve las aristas históricas-políticas-culturales que lo hacen sensible convivir en la sociedad; es un sujeto complejo que en uan sociedad hace eco de su subjetividad; pero no es sino es con el otro; permea la sociedad de garras de liberación de los instrumentos coloniales; este sujeto social altamente influyente se espera sea ejemplo de ciudadanía y de actor de lo que se espera de la conformación de una nueva civilización; pues permeando la sociedad, va a la tierra-patria como su casa sin igual. Comprende, y es lo deseado que dicho sujeto debe estar y ser en un mundo mejor, más sensible liberado. Deja atrás el sujeto social altamente colonizador marcador de prácticas opresivas que lo llevaron a continuar el proyecto modernista colonial.

Ahora es claro que necesitamos la noción de sujeto complejo, a la que de preeminencia la Educación Matemática Decolonial Transcompleja y que es histórica, política, cultural, social y planetaria. Pero altamente entramada con su hacer como ciudadano antropolítico y antropoético; vamos a ello en el paso esencial rizomático de la deconstrucción que es la reconstrucción; donde se vuelve a conectar con la crisis; pero emergiendo en rizomas de salidas con bellas hojas y frutos.

\section{Rizoma reconstrucción. La construcción del sujeto complejo en la Educación}

\section{Matemática Decolonial Transcompleja}

Hemos revisado categorías de sujetos histórico, políticos y social; todos imbricados en el sujeto cultural; de allí que dividir concepciones es imposible en tanto el sujeto es por su complejidad; "el sujeto complejo no es ya una máquina intelectual sino un ser vivo y afectivo en activo intercambio con su medio ambiente que incluye tanto la cultura humana como el ecosistema en su sentido más amplio" (NAJMANOVICH, 2017, p.25). ¿Qué aporta la EMDT al sujeto complejo? ¿Cómo se reconstruye el sujeto bajo las concepciones decoloniales, complejas y transdisciplinares de la matemática? Algunas de estas respuestas en acalorados rizomas inconclusos en el comienzo de la línea de investigación; llamada línea por un encuadre conveniente; pero son mesetas que por sí mismas se muestran muy imbricadas en el azaroso mundo del conocimiento transdisciplinar.

Se trata de un sujeto transgresor, "que en cierta manera supera la cultura que es dominante" (POZZILI, 2006, p. 4); que supere la matemática colonial, que la transgrede para 
RELACult - Revista Latino-Americana de Estudos em Cultura e Sociedade

Revista Latinoamericana de Estudios en Cultura y Sociedad | Revue Latino-américaine d'Études sur la culture et la société | Latin American Journal of Studies in Culture and Society V. 07, nº 01, jan.-abr., 2021, artigo n 2005 | claec.org/relacult | e-ISSN: 2525-7870

decolonizarla, a favor de y no en contra; cuestión que propende la complejidad; "jugar un doble juego entre la lógica y su transgresión" (MORÍN, 1984, pp. 346). Esta transgresión es una fuente de resistencia deseada en los actores educativos; que sabiéndose soslayados estén alerta a los procesos e instrumentos nuevos de colonialidad con la globalización.

La matemática que conforma a un ser realizado afectivo fuera de su afección de psique, para la libertad y autonomía y el discernimiento correcto en el pensar profundo, es "pensar un sujeto complejo, que es a la vez un cuerpo vivo e interactivo en intercambio permanente con su ambiente, ha llevado a una reconsideración del rol de las emociones a la hora de pensar nuestra condición humana" (NAJMANOVICH, 2017, p.40). Ese sujeto que atiende a la historia y filosofía de la matemática como renacer del patrimonio histórico de las civilizaciones es un sujeto constructor de historicidad, de cambios permanente a fin de salvaguardar el legado de la matemática.

Por ello, el sujeto complejo en la EMDT supera la antonimia de la reducción que impuso el docente con la ciencia más liberadora del planeta la matemática; por ello se propende que desde el sujeto en liberación se vaya a la "autogeneración de un proceso de incorporación de metacogniciones con el dialogo dialógico-dialéctico que en la dialógica con el Otro (POZZILI, 2006), y confrontando la contradicción que la lógica positivista enseña a rechazar la opresión y la implantación de las únicas vías reduccionistas de pensar y pensarse en la matemática; asumiendo lo etéreo, lo azaroso, lo contradictorio y la incertidumbre. "La contradicción puede por el contrario, señalarnos una capa profunda de la realidad que a nuestro entendimiento le resulta difícil de concebir (MORÍN, 1984, p.346).

El difícil arte de habitar en el planeta que propende la Educación Matemática Decolonial transcompleja propende que con la complejidad podemos "pensar un sujeto complejo que, como hemos visto, goza de autonomía ligada, pertenece a la naturaleza, y comprende que su existencia será siempre afectada por la de los otros con los que convive y con quienes coevoluciona" (NAJMANOVICH, 2017, p.44). Para ello, es importante decolonizar la ciencia matemática ante el Sur, ante la imposición occidental cargada de escepticismo de una matemática apartada para una élite denominados inteligentes; inclusive para la colonialidad en el sexo de los matemáticos, desde "luego en la matemática para Occidente, ha costado calar en el mero poder de eficiencia de que las mujeres somos capaces para la matemática, pese a claros ejemplos desde el comienzo de la ciencia" (RODRÍGUEZ, 2020a, p.12).

Se trata de ejercer en los sujetos educandos 
RELACult - Revista Latino-Americana de Estudos em Cultura e Sociedade

Revista Latinoamericana de Estudios en Cultura y Sociedad | Revue Latino-américaine d'Études sur la culture et la société | Latin American Journal of Studies in Culture and Society V. 07, $\mathrm{n}^{\circ}$ 01, jan.-abr., 2021, artigo $\mathrm{n}^{\circ}$ 2005 | claec.org/relacult | e-ISSN: 2525-7870

Una verdadera política educativa, una antropolítica que desmitificar que los currículos, el ejercicio de poder en el aula de la matemática como soslayación en las aspiraciones a educarse y llegar a ascender y construir cada día, re-construir sus teorías desde aplicabilidades nuestras, desde la cotidianidad y saberes soterrados desde el Sur (RODRÍGUEZ, 2020a, p.12).

Para pensar en la re-civilización del sujeto desde la EMDT, el sujeto complejo debe tomar conciencia que "aquel sujeto que aprendió a aferrarse a sus certezas y que se fiaba de una cosmovisión firme heredada de sus antepasados, ya no tiene cabida en este mundo actual" (POZZILI, 2006, p.6); porque esa ceguera colaboro en la crisis que tenemos; por ello el sujeto no puede permitirse encasillarse en los errores del pasado, "el sujeto comienza a autoobservarse ejerciendo su capacidad de sujeto histórico, lo que le permite recuperar su protagonismo y orientarse de un modo más autónomo" (POZZILI, 2006, p. 5).

En la decolonialidad planetaria, con la EMDT, en el arte del pensar profundo es urgente considerar al sentipensar, pensado de manera compleja entonces el sentipensamiento, afirma que el sentipensamiento es una síntesis afortunada (RODRÍGUEZ, 2020c), "porque condensa muy bien nuestro carácter estético primordial, dado que el sentimiento es de tal orden: antepuesto a todo ejercicio de pensar, sea cognitivo, ético, político o científico" (RESTREPO, 2016, p. 212). Es sin duda en sentipensar una categoría decolonial primerísima en la Educación Matemática que incita a imbuirse más allá de la racionalidad, hacia los procesos emotivos, es bien sabido que el cerebro aprende mejor, piensa profundo cuando se emociona y no se cohíbe con restricciones de la imaginación; en la tetra: cuerpo-mente-almaespíritu en plena complejidad en enseñanza (RODRÍGUEZ, 2020d).

El sentinpensar decolonial tiene una carga compleja subjetiva-objetiva donde se sale fuera del viejo debate cualitativo-cuantitativo-sociocritico en la forma de investigar; marca la apunta el sujeto investigador como víctima y doliente del caducado proceso se enseñanza modernista de la matemática y va como agente de cambio en la búsqueda de mesetas de salidas a la problemática (RODRÍGUEZ, 2020d). El sentipensar colabora en el abrazo de lo separado de la modernidad; los topoi, las separaciones impuestas por la modernidad, van a un ejercicio cotidiano; pero también científico de hacer matemática en la enseñanza (RODRÍGUEZ, 2020d).

Se trata de un sujeto que duda, y duda hasta de las propias verdades supuestas de la matemática, las complejiza y así observa como fue verdaderamente evolucionando el conocimiento de la matemática hasta llegar a las matemáticas fráctalicas; el sujeto de la duda es el sujeto complejo para la libertad de pensar e incisión en pensar cada vez más profundo. 
RELACult - Revista Latino-Americana de Estudos em Cultura e Sociedade

Revista Latinoamericana de Estudios en Cultura y Sociedad | Revue Latino-américaine d'Études sur la culture et la société | Latin American Journal of Studies in Culture and Society V. 07, nº 01, jan.-abr., 2021, artigo n 2005 | claec.org/relacult | e-ISSN: 2525-7870

El sujeto reflexivo hace alegoría de su propia colonialidad, de su adormecimiento; comienza a emerger en su pensamiento desde su interiorioridad u re-civilización que exterioriza en un comportamiento más humano; comprende el sujeto complejo como la matemática fue usada como arma mortal para soslayar (SKOVSMOSE, 2012). Por ello, el sujeto sale de la antonimia de la ceguera de su pensamiento y usa "el aporte de la cibernética de segundo orden es la de permitir ver lo que otros no ven" (LUHMANN, 1999, pp. 156)

El sujeto complejo devenido de la EMDT debe ser un sujeto re-ligante de sus propias prácticas; para pensar profundo complejamente con la matemática re-ligando es necesario ir a razonamiento es menester entonces que el docente se forme para optimizar la actividad cerebral del docente y de cómo desde actividades en clase puede explorar nuevas maneras de enseñar sin que tenga que recurrir al castigo de los errores, por ejemplo, que se cometen a la hora de resolver tareas en matemática (RODRÍGUEZ, 2020d). Es así como los actores del proceso educativo deben estar emocionados positivamente, deben adentrarse al juego de palabras y significancias son restricciones en el arte del pensar, jugando al geómetra, dilucidando a la logicidad (RODRÍGUEZ, 2020c).

El re-ligar (RODRÍGUEZ, 2019b) se manifiesta como el desafío de construir vías de diálogo y comprensión entre individuos, grupos, culturas y sociedades diferentes con la enseñanza de la matemática que contextualiza, pero también va la historia y filosofía de la matemática decolonialmente sin imponer modelos perse de enseñanza; es necesario regresar la historia y filosofía al aula unida a la lógica dialéctica como vía dialógica para aprender a pensar profundamente con la matemática (RODRÍGUEZ, 2020c).

En la EMDT, el sujeto debe conformarse de "una antropoética considerado el carácter ternario de la condición humana, (...) que convoca a la ciudadanía terrestre en el siglo XXI" (MORÍN, 2001b, p. 18). Se trata de un servicio responsable de su hacer como humano; de su peregrinar que lleva un apostolado: la matemática en la conformación y recivilización del sujeto; ese sujeto no escueto profundamente transdisciplinar que atiende a la condición humana primerísima de desmitificar ante la humanidad.

Sin duda, la primera y última condición de este sujeto complejo es que es un sistema, conformado por subsistemas de subsistemas, integrante de una familia, de una sociedad, de una comunidad, de una especia, de la tierra y dependiente de la tríada: individuo-sociedad y especie. Integraciones que retroalimentan otras integraciones que las contienen, y así se multiplican y retroalimentan entre sí en redes de sistemas entre las que hay interacción; entre ellas las de los grupos de colaboradores transdisciplinares de las ciencias; del abrazo de los saberes que transversalizan el conocer. De allí, "que haya una coincidencia epistemológica 
RELACult - Revista Latino-Americana de Estudos em Cultura e Sociedade

Revista Latinoamericana de Estudios en Cultura y Sociedad | Revue Latino-américaine d'Études sur la culture et la société |

entre los conceptos de interacción, sistema y red, que describen el modo de organización de las realidades vivas complejas, en las que el elemento simple se ha desintegrado" (MORÍN, 1984, p.345).

Nótese que la matemática decolonial, transdisciplinar y compleja en el individuo entonces converge en un sujeto dialógico-dialectico; el dialogo dialéctico está orientado a la “discriminación entre verdad y error mediante el pensamiento" (PANIKKAR, 1999, p.27), este tipo de diálogo parte de la hipótesis de que los participantes cooperan en una racionalidad, como el principio de no contradicción, y de ese modo pueden someter sus perspectivas a la audiencia de la razón; ello se pretende aplicar en los conceptos de la matemática y se conoce de los diálogos de Platón, Sócrates entre otros. Panikkar (2003) piensa que el diálogo dialéctico, si bien tiene su lugar en ciertos ámbitos de la vida humana, es insuficiente para asumir los retos de la interculturalidad; así en la educación la comunicación es posible y debe ocurrir en un nivel diferente al de la dialéctica; pero desde luego no divorciada de ella.

Por ello, Raimon Panikkar va la dialogo dialógico, y afirma que,

En el diálogo dialógico somos conscientes de que los conceptos que utilizamos brotan de una fuente más profunda. No solo permito que el otro me conozca sino que llego a conocer mejor mi propio mythos mediante las críticas y descubrimientos de mi interlocutor. El diálogo dialógico no tiene ni a la victoria en el contexto de las ideas ni a un acuerdo que suprima una auténtica diversidad de opiniones. El diálogo dialógico busca, si acaso, expandir el campo de comprensión, con la profundización por parte de cada interlocutor de su propio campo de comprensión y la apertura de un posible lugar para lo (¿todavía?) no comprendido (PANIKKAR, 2003, p.67).

Como podemos ver, el diálogo dialéctico es sobre objetos, en este caso matemáticos, sobre sus doctrinas, temas o problemas que se tratan en la ciencia; pero el diálogo dialógico es entre sujetos, entre docentes y discentes, porque el dialogo entre ellos en la Educación Matemática es sobre ellos mismos y de ese modo consiguen entrar cada uno en el universo cultural del otro; para ello e imperativo considerar la cultura, cotidianidad de la matemática; cuestión posible en la decolonialidad planetaria donde la Educación Matemática y la matemática toma en cuenta la complejidad y toda extensión de los aportes matemáticos; inclusivos del Sur y de los países soslayados.

Es más, el diálogo dialógico asume un radical dinamismo de la realidad, esto es, "que la realidad no es dada de una vez para siempre, sino es real justamente por el hecho de que está continuamente creándose a sí misma y no simplemente desarrollándose a partir de premisas y puntos de partida preexistentes” (PANIKKAR, 1999, p.38) ¿Cómo es posible este encuentro dialógico-dialéctico en la Educación Matemática? Como se afirmó, el diálogo 
RELACult - Revista Latino-Americana de Estudos em Cultura e Sociedade

Revista Latinoamericana de Estudios en Cultura y Sociedad | Revue Latino-américaine d'Études sur la culture et la société |

dialógico no se basa en la discusión de conceptos de la matemática y educación, sino que utiliza como su instrumento los símbolos de la cultura matemática. La diferencia entre concepto matemático y el símbolo que lo representa es aquí esencial. Con ello vemos que Panikkar (2003) es posible y necesario el diálogo dialéctico, así como el diálogo dialógico.

Un sujeto dialógico-dialéctico desarrolla estructuras profundas metacognitivas que van a colaborar en ese el difícil arte de habitar en el planeta; de ello la EMDT aporta esencias para un individuo emotivo, afectivo, racional, espiritual que colabore en la convivencia altamente humana que se necesita para la recivilización de la humanidad.

\section{Rizoma cierre. Conclusiones de primicias}

Propendemos la conformación del sujeto complejo en la Educación Matemática Decolonial Transcompleja como objetivo complejo de investigación. Emmarcada en la línea de investigación: Educación Matemática Decolonial Transcompleja. Todo ello lo hemos realizado con la deconstrucción como transmétodo bajo una construcción rizomática.

La construcción del sujeto en la Educación Matemática es una tarea imposible bajo el proyecto colonial; pero en la decolonialidad planetaria de la EMDT comienza a despertar el oscurantismo de la parcelación del sujeto. Este sujeto complejo desde luego atiende a una carga histórica, política, social, cultural que llegando al complexus entramado de su ser atiende a la compleja concepción de la matemática.

La liberación onto-epiestemológica de los sujetos en la EMDT es de vital importancia, su concienciación sólo es posible en una liberación de sus ser y manera de conocer; para que el vaya criticamente a transformar la realidad de la Educación Matemática decandente; y para que vaya engrandeciendo las salidas a la crisis; es necesario para ello, un constante des-ligar y re-ligar en la liberación. Con especial atención a la mutación de los artefactos de poder que se van inmiscuyendo en la globalización para la colonialidad de la matemática. Sus sujetos liberados deben ir a promove runa matemática con único apellido: la humanidad; a la que todos tienen derecho aprender y disfrutar de sus bonanzas.

Es de hacer notar que la línea de investigación Educación Matemática Decolonial Transcompleja esta en pleno ardor investigativo; en ella se han publicado investigaciones como: Rodríguez (2020e) y Rodríguez (2020f). Es de hace notar que estas líneas que transgestiona su autora se llevan de la mano de sus transmétodos; como el que se viene usando en esta investigación: las deocnstrucción rizomática como transmétodo y por ejemplo la hermenéutica comprensiva, ecosófica y diatópica en Rodríguez (2020f). e recomeinda su 
RELACult - Revista Latino-Americana de Estudos em Cultura e Sociedade

Revista Latinoamericana de Estudios en Cultura y Sociedad | Revue Latino-américaine d'Études sur la culture et la société |

lectura para las visioens decoloniales y rizomáticas enmarcadas en la transcomplejidad que van enmarañando formando mesetas investigativas.

Para despedirnos con el Espíritu Santo de Dios que nos da la sabiduría en el arte de pensar profundo, de formarnos como sujetos realmente humanos y el respeto por la vida; creador Dios amado de la matemática que tus hijos alumbrados por tu amor develan para hacer tu obra en esta tierra: "¡Cuán preciosos también son para mí, oh Dios, tus pensamientos! ¡Cuán inmensa es la suma de ellos! Si los contara, serían más que la arena; al despertar aún estoy contigo" (Salmos 139: 17-18). Bendiciones a todos en el nombre de nuestro Señor Jesucristo.

\section{Referencias}

ANDRADE, J.; LEGUIZAMO, D.; VERGARA, A. Educación para la resistencia, una aproximación desde la complejidad. Revista Kalivando, v.10, p.2, p.495-508, 2018.

CARABAllO, M.; RODRÍGUEZ, M. E. Perspectivas complejas y antropoéticas de la Educación Inclusiva Ecosófica. Polyphōnia. Revista de Educación Inclusiva, v.3, n.2, p.117133, 2019.

DELEUZE, G.; GUATTARI, F. Mil mesetas. Capitalismo y esquizofrenia. Valencia: Ediciones Pre-Texto, 2002.

DUSSEL, E. Sobre el sujeto y la intersubjetividad: el agente histórico como actor en los movimientos sociales. Revista Pasos, v.84, 1-18, 1999.

FOUCAULT, M. Por qué estudiar el poder: la cuestión del sujeto. En: AA.VV., Materiales de sociología crítica. Ediciones La Piqueta: Madrid, 1986.

FOUCAULT, M. Por qué estudiar el poder: la cuestión del sujeto. En Dreyfus, H. y Rabinow, P., Michel Foucault. Más allá del estructuralismo y la hermenéutica. Buenos Aires, Nueva Visión, 2001.

FOUCAULT, M. Vigilar y castigar nacimiento de la prisión. Argentina: Siglo XXI, 2008.

FOUCAULT, M. El Orden Del Discurso. Barcelona: Fábula, 1990.

GIDENNS, A. Modernidad e Identidad del Yo. El Yo y la Sociedad en la Época Contemporánea. Barcelona: Ediciones Península, 1995.

LUHMANN, N. El programa de conocimiento del constructivismo y la realidad que permanece desconocida. Teoría de los sistemas sociales II. Bogotá: Universidad Iberoamericana/Colección Teoría Social, 1999.

MAFFESOLI, M. El Tiempo de las Tribus. El ocaso del individualismo en las sociedades posmodernas de Michel Maffesoli. Argentina: Siglo XXI Editores, 2004. 
RELACult - Revista Latino-Americana de Estudos em Cultura e Sociedade

Revista Latinoamericana de Estudios en Cultura y Sociedad | Revue Latino-américaine d'Études sur la culture et la société |

MORÍN, E. Ciencia con Conciencia. Barcelona: Editorial Anthropos, 1984

MORÍN, E. Introducción al Pensamiento Complejo. Barcelona: Gedisa, 2001a.

MORÍN, E. Los siete saberes necesarios para la educación del futuro. Paidós: Barcelona, $2001 b$.

MORÍN, E. La Cabeza bien puesta. Buenos Aires: Ediciones Nueva Visión, 2002.

NAJMANOVICH, D. El sujeto complejo: La condición humana en la era de la red. Estudios Utopía y Praxis Latinoamericana, v. 22, n. 78, p.25-48, 2017.

PANIKKAR, R. The Intrareligious Dialogue. New York: Paulist Press, 1999.

PANIKKAR, R. El diálogo indispensable: Paz entre las religiones. Barcelona: Península, 2003.

PÉREZ, A. Las matemáticas modernas: pedagogía, antropología y política. Entrevista a George Papy. Perfiles Educativos, n.10, p.41-46, 1980.

POZZOLI, M. El sujeto de la complejidad. Polis, 15, 1-17, 2006

RESTREPO, G. Seguir los pasos de Orlando Fals Borda: religión, música, mundos de la vida y carnaval. Investigación \& Desarrollo, v. 24, n. 2, 2016, p. 199-239, 2017.

RODRÍGUEZ, M. E. Deconstrucción: un transmétodo rizomático transcomplejo en la transmodernidad. Sinergias educativas, v.4, n.2, 2019a. DOI: https://doi.org/10.31876/s.e.v4i1.35

RODRÍGUEZ, M. E. Re-ligar como práctica emergente del pensamiento filosófico transmoderno. ORINOCO Pensamiento y Praxis, v.11, p.13-3, $2019 \mathrm{~b}$.

RODRÍGUEZ, M. E. Visiones rizomáticas de la enseñanza de la matemática como decolonialidad. IE revista de investigación educativa de la Rediech, v. 11, e836, p.1-17, 2020a. DOI: https://doi.org/10.33010/ie_rie_rediech.v11i0.836

RODRÍGUEZ, M. E. Estrategias complejas en la resolución de problemas matemáticos contextualizados. Educação, Escola \& Sociedade, v. 13, n. 15, e202007, p. 1-20, 2020b. DOI: https://doi.org/10.46551/ees.e202007

RODRÍGUEZ, M. E. ¡Pienso, por lo tanto soy! dejando la pereza intelectual: un re-ligar que convoca a pensar matemáticamente. Revista de Educação Matemática, São Paulo, SP, v. 17, 2020, p. 1-15, e020044, 2020c. DOI: https://doi.org/10.37001/remat25269062v17id398

RODRÍGUEZ, M. E. Serendipiando con los procesos mentales de la matemática en la complejidad en sentipensar decolonial. RIFP Revista Internacional de Formación de Professores, v.5, e020012, p. 1-23, 2020d. 
RODRÍGUEZ, M. E. El des-ligaje de la biopolítica para el re-ligaje en la Educación Matemática Decolonial Transcompleja. Educação Matemática Debate, v. 4, n.10, e202057, p. 1-19, 2020e. DOI: 10.46551/emd.e202057

RODRÍGUEZ, M. E. Matemática-ecosofía: miradas de un acercamiento complejo. Visión Educativa IUNAES, v.14, n.29, p.1-12, 2020 f.

RODRÍGUEZ, M. E. La hermenéutica comprensiva, ecosófica y diatópica: un transmétodo rizomático en la transmodernidad. Revista Perspectivas Metodológicas, v. 19, p.1-15, 2020g. DOI: https://doi.org/10.18294/pm.2020.2829

SANTOS, B. Crítica de la Razón Indolente Contra el Desperdicio de la Experiencia, Volumen I, Para un Nuevo Sentido Común: La Ciencia, El Derecho y La Política En La Transición Paradigmática. Bogotá: Editorial Desclée De Brouwer, S.A, 2003.

SKOVSMOSE, O. Investigación, práctica, incertidumbre y responsabilidad. En P. Valero y O. Skovsmose, Educación matemática crítica. Una visión sociopolítica del aprendizaje y la enseñanza de las matemáticas (pp. 261-370). Colombia: Universidad de los Andes, Centro de Investigación y Formación en Educación, 2012.

TOLEDO, M. Sobre la construcción Identitaria. Atenea, 506, p. 43-56, 2012.

ZOURABICHVILI, F. El vocabulario Deleuze. Buenos Aires: Ediciones Atuel, 2007. 
RELACult - Revista Latino-Americana de Estudos em Cultura e Sociedade

Revista Latinoamericana de Estudios en Cultura y Sociedad | Revue Latino-américaine d'Études sur la culture et la société |

Latin American Journal of Studies in Culture and Society

V. 07, $\mathrm{n}^{\circ}$ 01, jan.-abr., 2021, artigo $\mathrm{n}^{\circ} 2005$ | claec.org/relacult | e-ISSN: 2525-7870

\title{
A construção do sujeito complexo na Educação Matemática Decolonial Transcomplex
}

\begin{abstract}
Resumo
O assunto que vem da pedagogia da matemática tradicional é contornado; a escolarização impõe normas que estabelecem uma ordem e relações reprodutivas que nos obriga a assimilar e repetir os saberes estabelecidos pela racionalidade hegemônica. Na consciência ecossófica, na ecosofia, na arte de habitar o planeta, tendemos a moldar o assunto complexo na Educação Matemática Decolonial Transcomplex como um objetivo complexo de pesquisa. A pesquisa é realizada a partir da desconstrução como um transmétodo rizomático na transmodernidade. No rizoma reconstrutivo, o sujeito crítico consciente em um diálogo dialético-dialético, conforma-se como cidadão do planeta-terra na antropoética; da Educação Matemática. É imperativo, portanto, um distanciamento das práticas opressivas da matemática; religar o sujeito político que exerce o poder, que transita no conhecimento da matemática complexa com a contribuição das civilizações colonizadas, em processos descoloniais claros; e o cotidiano do habitat popular; em uma liberação onto-epistemológica do sujeito. Quebrando a imposição ocidental da matemática.
\end{abstract}

Palavras-chave: Construção; Assunto complexo; Educação matemática; Decolonial; Transcomplex.

\section{La construction du sujet complexe dans l'enseignement des mathématiques transcomplexes décoloniales}

\begin{abstract}
Résumé
Le sujet issu de la pédagogie des mathématiques traditionnelles est contourné; la scolarité impose des normes qui établissent un ordre et des relations reproductives qui nous obligent à assimiler et à répéter les connaissances établies par la rationalité hégémonique. Dans la conscience écosophique, l'écosophie, l'art d'habiter la planète, nous avons tendance à façonner le sujet complexe de l'éducation mathématique décoloniale transcomplexe comme un objectif de recherche complexe. La recherche est menée à partir de la déconstruction comme méthode de transmission rhizomatique en transmodernité. Dans le rhizome reconstructeur, le sujet consciencieux critique dans un dialogue dialectique-dialogique, se conforme comme citoyen de la planète-terre à l'anthropoétique; de l'enseignement des mathématiques. Il est donc impératif, un détachement des pratiques oppressives des mathématiques; de relier le sujet politique qui exerce le pouvoir, qui transite par la connaissance de mathématiques complexes avec l'apport des civilisations colonisées, dans des processus décoloniaux clairs; et la vie quotidienne de l'habitat populaire; dans une libération surépistémologique du sujet. Rompre l'imposition occidentale des mathématiques.
\end{abstract}

Mots-clés: Construction; Sujet complexe; Enseignement des mathématiques; Décolonial; Transcomplexe.

\section{The construction of the complex subject in Transcomplex Decolonial Mathematics Education}

\begin{abstract}
The subject that comes from the pedagogy of traditional mathematics is bypassed; schooling imposes norms that establish an order and reproductive relationships that oblige us to assimilate and repeat the knowledge established by hegemonic rationality. In ecosophic awareness, ecosophy, the art of inhabiting the planet, we tend to shape the complex subject in Transcomplex Decolonial Mathematical Education as a complex research objective. Research is carried out from deconstruction as a rhizomatic transmethod in transmodernity. In the reconstructive rhizome, the critical conscious subject in a dialectical-dialogical dialogue, is conformed as a citizen of the planet-earth in anthropoetics; from Mathematics Education. It is imperative thus, a detachment of the oppressive practices of mathematics; to re-link the political subject that exercises power, that transits in knowing complex mathematics with the contribution of colonized civilizations, in clear decolonial processes;
\end{abstract}


RELACult - Revista Latino-Americana de Estudos em Cultura e Sociedade

Revista Latinoamericana de Estudios en Cultura y Sociedad | Revue Latino-américaine d'Études sur la culture et la société | Latin American Journal of Studies in Culture and Society V. 07, nº 01, jan.-abr., 2021, artigo nº 2005 | claec.org/relacult | e-ISSN: 2525-7870

and the daily life of the popular habitat; in an onto-epistemological liberation of the subject. Breaking the Western imposition of mathematics.

Keywords: Building; Complex subject; Mathematics education; Decolonial; Transcomplex. 